\title{
Depression and Diabetes in High-Risk Urban Population of Pakistan
}

\author{
Fareeha Faisal $^{*}, 1$, Shaheen Asghar ${ }^{2}$, M. Zafar Iqbal Hydrie ${ }^{1,3}$, Asher Fawwad ${ }^{4}$, Abdul Basit ${ }^{5}$, \\ A. Samad Shera ${ }^{6}$ and Akhtar Hussain ${ }^{7}$
}

\author{
${ }^{I}$ Baqai Institute of Diabetology and Endocrinology, Baqai Medical University, Plot No. 1-2, II-B, Nazimabad No. 2, \\ Karachi-74600, Pakistan \\ ${ }^{2}$ Institute for Psychiatric Research, Section-Aker University Hospital, Clinic for Mental Health, Sognsvannsveien 21, \\ 0320 Oslo, Norway \\ ${ }^{3}$ Department of International Health, Institute of General Practice and Community Medicine, Faculty of Medicine, \\ University of Oslo, Norway \\ ${ }^{4}$ Research Department, Baqai Institute of Diabetology and Endocrinology, Baqai Medical University, Plot No. 1-2, II-B, \\ Block 2, Nazimabad, Karachi-74600, Pakistan \\ ${ }^{5}$ Department Medicine, Baqai Institute of Diabetology and Endocrinology, Baqai Medical University, Plot No. 1-2, II-B, \\ Block 2, Nazimabad, Karachi-74600, Pakistan \\ ${ }^{6}$ WHO Collaborating Centre, Diabetic Association of Pakistan, 5-E/3, Nazimabad, Karachi-74600, Pakistan \\ ${ }^{7}$ Faculty of Medicine, Institute of General Practice and Community Medicine, Department of International Health, \\ University of Oslo, P.O. Box 1130, Blindern, N-0317, Oslo, Norway
}

\begin{abstract}
Objective: To determine the prevalence of depressive symptoms among subjects with high-risk of diabetes as assessed by a pre-defined questionnaire in an urban city of Pakistan. Depressive symptoms were also assessed in people with newly diagnosed diabetes along with its determinants.

Materials and Methods: High risk subjects were identified by a pre-defined questionnaire which included positive family history of DM, age > $30 \mathrm{yrs}$, obese or over weight, decreased intake of fruit and vegetables in diet etc. Amongst them 1,825 subjects agreed for OGTT. 1,246 subjects gave consent for the assessment of depressive symptoms. Depressive symptoms were assessed by using the Montgomery Asberg Depression Rating Scale (MADRS).

Results: Depressive symptoms were present in $7.4 \%$ of the subjects at a rating of $\geq 13$ on the MADRS. Mean age of all the subjects was $42 \pm 9.4$ years while mean BMI was $26.3 \pm 5.1 \mathrm{~kg} / \mathrm{m}^{2}$. The prevalence of depression was significantly higher in subjects with newly diagnosed diabetes compared to subjects without diabetes $(13 \%$ vs $6 \% ; \mathrm{p}<0.01)$. Females were found to be more depressed than males $(15.5 \%$ vs $3.6 \% ; \mathrm{p}<0.001)$. Female gender, being financially dependent, and having diabetes were found to be independent risk factors for depression controlling for potential confounding factors.

Conclusion: A significantly high percentage of depression, assessed by MADRS was found in subjects with newly diagnosed diabetes as compared to subjects without diabetes. It is of the essence that psychiatric attention may be necessary to be incorporated in diabetes care both for prevention and treatment.
\end{abstract}

Keywords: Depression, newly diagnosed diabetes, high risk population, Pakistan, MADRS.

\section{INTRODUCTION}

Diabetes prevalence has been increasing worldwide and according to World Health Organization (WHO) estimates, the number of people with diabetes will rise from 246 million in 2007 to 380 million by 2025 [1].

Depression is a common public health issue which affects all aspects of a person's life and has been recognized as an important co-morbid condition in diabetes [2]. Studies

*Address correspondence to this author at the Baqai Institute of Diabetology and Endocrinology, Baqai Medical University, Plot No. 1-2, II-B, Nazimabad No 2, Karachi-74600, Pakistan; Tel: 9221 36688897, 9221 36608565, 9221 316707179; Fax: 9221 36608568;

E-mail: research@bideonline.com have identified depression as an independent risk factor for type 2 diabetes with relative risk of developing diabetes ranging from 1.3 to 3.0 [3-7].

It has been observed that depression frequently co-exists with diabetes and diabetes-related complications [8-10]. Evidence suggests that subjects with diabetes who have co morbid depression not only have poor glycemic control but also have higher rate of diabetes complications and disability [11]. Different trials have suggested that improvement in glycemic control is correlated with improvement in depression [12-14], while some studies have found association between glucose dysregulation and depression before the onset of type 2 diabetes [3, 4, 15]. 
The combination of depression and diabetes has a detrimental effect on an individual's health and it adversely affects the chances of a healthy recovery from illness [16]. We know that depression not only decreases the quality of life in subjects with diabetes but may also worsen their glycemic control and this in turn may result in increased occurrence of complications resulting in higher health-care economic burden on individuals and the society at large [17, 18].

To the best of our knowledge the data on the prevalence of depression in subjects with high risk of diabetes in an urban population in Pakistan is limited. We investigated the prevalence of depression in subjects with high risk of diabetes as defined by being overweight, having positive family history, physically inactive and poor dietary habits in an urban population of Pakistan. Risk indicators for depression in relation to socio-economic state, education, marital status and diabetes were also assessed.

\section{MATERIAL AND METHODS}

Screening camps were organized at various schools, union council offices and factories in and around the city of Karachi, Pakistan as part of a diabetes primary prevention program. On the first day of the program diabetes awareness lectures were delivered to the general public and employees by health professionals of the prevention team. On the second day, subjects identified as high risk on the basis of a questionnaire about weight, positive family history, physically inactivity and poor dietary habits etc were asked for an Oral Glucose Tolerance Test (OGTT). Individuals more than 30 years of age with no previous history of diabetes were included in the study. On the day of OGTT, subjects came with a fasting of 8-10 hrs. Fasting blood sample was taken and they were given a drink containing 75 gms of glucose with the time noted. Depression was assessed by MADRS after taking the fasting sample of blood. Second blood sample was taken two hrs after the glucose load. A total of 1,825 high risk subjects agreed for OGTT. Blood glucose was estimated by the oxidase method (GOD-PAP) [19]. Diabetes was defined according to WHO diagnostic criteria of $\mathrm{RBS} \geq 200 \mathrm{mg} / \mathrm{dl}$ [20].

Depression was assessed by Montgomery Asberg Depression Rating Scale (MADRS) developed by Montgomery and Asberg in 1979 [21]. MADRS is a 10 items questionnaire. The sum of each item is from 0 to 6 and total sum of the questionnaire ranges from 0-60. Normally, MADRS scores are categorized into 4 groups, Healthy $(0-$ 12), Mild depression (13-19), Moderate depression (20-34), and severe depression (35-60) [22]. 1,246 subjects gave consent for the assessment of depressive symptoms. To ensure standardization, a single health professional did the MADRS scoring of all the individuals.

Demographic and socioeconomic information was also collected through a structured questionnaire. Subjects were categorized according to age into two groups, $<40$ and $\geq 40$ yrs. Height was measured in centimeters and weight was measured in kilogram BMI was calculated by dividing weight to height in meter square. According to WHO and IDF definition, obesity in Asians is defined as BMI $25 \mathrm{~kg} / \mathrm{m}^{2}$ and above [23]. BMI values were categorized into obese $(\geq 25)$ and non obese $\left(<25 \mathrm{~kg} / \mathrm{m}^{2}\right)$. Waist and hip girth was measured and blood pressure was recorded by using a mercury sphygmomanometer Waist circumference was measured with non stretchable measuring tape at the midpoint between bottom rib and tip of hip bone. Hip circumference was measured at the fullest part of the hips.

We divided our subjects into two groups, 0-12 as healthy subjects and above 13 as depressed subjects as defined in a study done in a rural area of Pakistan [22]. The term depression is used in terms of an epidemiological definition based on symptoms scale [24].

The ethical approval for this study was given both by the Norwegian Ethical Committee for Medical Research and by the Institutional Review Board of Baqai Institute of Diabetology and Endocrinology (BIDE).

\section{Statistical Analysis}

The data was entered and analyzed on SPSS version 13.0. Continuous variables are shown as Mean \pm SD and categorical variables are in frequencies and percentages.

T-test was used for the mean difference of two groups and compared with $\mathrm{p}$ value $<0.05$ for the statistical significance. Z-test for proportion is used for the prevalence with the same criteria of significance. Logistic regression is used to get the adjusted odds ratio and 95\% CI for sex, age, diabetes, BMI, marital status, occupation, education, socioeconomic status and hypertension.

\section{RESULTS}

Out of the 1,246 subjects, $853(68.4 \%)$ were males and $393(31.5 \%)$ were females. One hundred and seven $(8.5 \%)$ had diabetes but no depression, $76(6 \%)$ were depressed without diabetes, $16(1.28 \%)$ had both diabetes and depression, while 1047 (84\%) were free from both diabetes and depression. Depression with diabetes was relatively common in the older age group having a mean age of $44.6 \pm$ 10.5 years. Depressed subjects and subjects with diabetes had significantly high BMI as compared to healthy subjects with a $p$ value of $<0.05$ as shown in Table 1 . Systolic and diastolic blood pressure was also high amongst those having both diabetes and depression. Mean age of all the subjects was $42 \pm 9.4$ years while mean BMI was $26.3 \pm 5.1 \mathrm{~kg} \backslash \mathrm{m}^{2}$ (data not shown in Table 1).

Prevalence of depression was found to be $7.4 \%$ in this population (Table 2). The prevalence of symptoms of depression was significantly higher 13\% (95\% CI; 8.03 $18.95)$ in subjects with diabetes as compared to subjects without diabetes $6.8 \%(95 \% \mathrm{CI} ; 5.53-8.23)$ as shown in Table 2 ( $\mathrm{p}$ value $=0.01$, Odds ratio $2.1,95 \% \mathrm{CI} ; 1.1-3.6$ ) Depression was more common in subjects whose BMI was > $25 \mathrm{~kg} \backslash \mathrm{m} 2$ i.e. $9.1 \%$ with a OR 1.4 (95\% CI 0.92- 2.35) compared to non obese. Looking at the gender distribution females were more depressed as compared to males $(15.5 \%$ vs $3.6 \%$; $<<0.005$ ) as shown in Table 2 .

Being female, having diabetes and being socioeconomically dependent (non earners and not included as income generating members of the family) were significant 
Table 1. Characteristics of Sample Population

\begin{tabular}{|c|c|c|c|c|}
\hline Characterstics & $\begin{array}{c}\text { Healthy (No Diabetes } \\
\text { and No Depression) }\end{array}$ & $\begin{array}{l}\text { Depressed but No } \\
\text { Diabetes }\end{array}$ & $\begin{array}{l}\text { Diabetes but No } \\
\text { Depression }\end{array}$ & $\begin{array}{c}\text { Both Diabetes and } \\
\text { Depression }\end{array}$ \\
\hline $\mathrm{n}=1246$ & 1047 & 76 & 107 & 16 \\
\hline \multicolumn{5}{|l|}{ Demographic Parameters } \\
\hline Age in years & $41.4 \pm 9.3$ & $41.9 \pm 8.9$ & $43.7 \pm 9.5 *$ & $44.6 \pm 10.5$ \\
\hline Males \% & $754(72 \%)$ & $27(35.5 \%)$ & $68(63.6 \%)$ & $4(25 \%)$ \\
\hline Females \% & $293(27.9 \%)$ & $49(64.5 \%)$ & $39(36.4 \%)$ & $12(75 \%)$ \\
\hline High Physical activity & $441(42.12 \%)$ & $25(32.89 \%)$ & $44(41.12 \%)$ & $7(43.75 \%)$ \\
\hline Low Physical activity & $606(57.9 \%)$ & $51(67.1 \%)$ & $63(58.9 \%)$ & $9(56.3 \%)$ \\
\hline \multicolumn{5}{|l|}{ Anthropometric Parameters } \\
\hline Body mass index $(\mathrm{kg} / \mathrm{m} 2)$ & $26.1 \pm 4.9$ & $27.9 \pm 5.8 *$ & $27.8 \pm 6.5 *$ & $26.4 \pm 5.2$ \\
\hline Waist-hip ratio & $1.07 \pm 3.8$ & $0.84 \pm 0.2$ & $0.88 \pm 0.2$ & $0.86 \pm 0.1$ \\
\hline Systollic blood pressure $(\mathrm{mm} / \mathrm{Hg})$ & $120 \pm 17$ & $120 \pm 17$ & $121 \pm 18$ & $127 \pm 16$ \\
\hline Diastolic blood pressure $(\mathrm{mm} / \mathrm{Hg})$ & $84 \pm 11$ & $84 \pm 11$ & $84 \pm 14$ & $89 \pm 10$ \\
\hline
\end{tabular}

$*$ p-value $<0.05$ was observed when compared with healthy subjects.

Values Present as Mean \pm SD and $n(\%)$.

independent risk indicators for depression in this population (Table 3). It appears that low income was a modifier in the multivariate model (OR 2.2, 95\% CI 0.86- 5.62; p-value $=0.097$ ).

\section{DISCUSSION}

Prevalence of depression in this population was found to be $7.4 \%$, which is relatively low when compared with other studies done in different areas of Pakistan that reported 34\% and $48.8 \%$ cases of depression in their respective populations $[25,26]$. This difference in the prevalence is likely due to the different assessment tools used for the symptoms of depression. In the Primary Prevention Program, a high risk group for diabetes was initially identified on the basis of a structured questionnaire and these were further screened by Oral Glucose Tolerance Test. Those who were identified as having diabetes according to OGTT were labeled as newly diagnosed subjects with diabetes. Assessment of depression by MADRS was done at baseline before the second sample was taken as a component of the diabetes primary prevention program..

The reported prevalence rate of depression from rural area of Pakistan by using MADRS was 5.4\%, which is comparable to our results [22]. A possible reason for the low prevalence of depression could be under reporting of subjects with depression because people were reluctant to tell about depressive symptoms as they did not want to accept themselves as a patient of depression. Both in Bangladesh and Pakistan depression was associated with low income.

Table 2. Prevalence of Depression with $95 \%$ CI

\begin{tabular}{|l|c|c|c|c|c|c|c|c|c|}
\hline \multirow{2}{*}{} & \multicolumn{4}{|c|}{ Over All } & \multicolumn{4}{c|}{ Male } & \multicolumn{2}{c|}{ Female* } \\
\cline { 2 - 10 } & $\mathbf{n}$ & Depression & $\mathbf{( 9 5 \%}$ CI) & $\mathbf{n}$ & Depressed & $\mathbf{( 9 5 \%}$ CI) & n & Depressed & (95\% CI) \\
\hline \hline All & 1246 & 92 & $7.38(6.16-8.83)$ & 853 & 31 & $3.63(2.58-4.89)$ & 393 & 61 & $15.52(12.52-19.1)$ \\
\hline Age $<40$ years & 577 & 39 & $6.75(5.04-8.8)$ & 403 & 15 & $3.72(2.17-5.57)$ & 174 & 24 & $13.79(9.5-18.9)$ \\
\hline Age $>40$ years & 669 & 53 & $7.92(6.2-9.96)$ & 450 & 16 & $3.55(2.12-5.26)$ & 219 & 37 & $16.89(12.74-21.85)$ \\
\hline Without DM & 1123 & 76 & $6.76(5.53-8.23)$ & 781 & 27 & $3.45(2.38-4.73)$ & 342 & 49 & $14.32(11.22-18.04)$ \\
\hline With DM & 123 & 16 & $13(8.03-18.95)$ & 72 & 4 & $5.55(1.12-0.84)$ & 51 & 12 & $23.52(13.78-35.17)$ \\
\hline BMI $>=25 \mathrm{~kg} / \mathrm{m}^{2}$ & 645 & 59 & $9.14(7.28-11.37)$ & 380 & 14 & $3.68(2.09-5.57)$ & 265 & 45 & $16.98(13.19-21.5)$ \\
\hline BMI $<25 \mathrm{~kg} / \mathrm{m}^{2}$ & 438 & 28 & $6.39(4.47-8.68)$ & 336 & 14 & $4.16(2.37-6.3)$ & 102 & 14 & $13.72(8.13-20.4)$ \\
\hline WHR $\geq$ cut off & 794 & 63 & $7.93(6.36-9.81)$ & 597 & 23 & $3.85(2.56-5.39)$ & 197 & 40 & $20.3(15.6-25.92)$ \\
\hline WHR $<$ cutoff & 452 & 29 & $6.42(4.52-8.67)$ & 256 & 8 & $3.12(1.34-5.25)$ & 196 & 21 & $10.7(7.09-15)$ \\
\hline
\end{tabular}

*All $\mathrm{p}$ values were $<0.005$ while compared with male to female.

T2DM= Type 2 Diabetes Mellitus.

BMI= Body Mass Index.

WHR= Waist-hip ratio.

Cut off values of WHR $=0.9 \mathrm{~cm}$ for male and $0.8 \mathrm{~cm}$ for female. 
Table 3. OR with $95 \%$ CI for Depression

\begin{tabular}{|c|c|c|c|}
\hline Variables & Adjusted Odds Ratio* & $95 \%$ CI & p-Value \\
\hline Female & 6.48 & $3.43-12.26$ & 0.000 \\
\hline Age above 40 years & 1.09 & $0.60-1.98$ & 0.767 \\
\hline Subjects with diabetes & 3.81 & $1.7-8.53$ & 0.001 \\
\hline Obese Subjects & 1.05 & $0.55-2.02$ & 0.861 \\
\hline Unmarried & 2.15 & $0.79-5.81$ & 0.13 \\
\hline Low income status & 2.2 & $0.86-5.62$ & 0.097 \\
\hline Under graduate & 0.51 & $0.22-1.17$ & 0.111 \\
\hline Financially dependent & 7.75 & $4.17-14.41$ & 0.000 \\
\hline Hypertension & 1.31 & $0.74-2.33$ & 0.345 \\
\hline
\end{tabular}

We found significantly high percentage of depression in our diabetic population, a trend that was also seen in other studies from this region $[3,24]$. Our results showed high percentage of depression in females as compared to males, this has also been observed in other studies [24].

This higher prevalence of depression in females may be due to women bearing more stress in our social and cultural set up along with the added responsibility of the role of caretaker of the whole family [26]. Furthermore, as women are more economically dependent in our society this could be a cause of high percentage of depression.

Result shows depression was common in group of subjects who were non-earners, less educated and belonging to low income group. Along with these factors, diabetes and increasing age were also positively associated with depression; similar trend was also observed in a study from rural community of Pakistan [22]. We also observed that dependent persons (non-earners) were more depressed than earners, as they were not contributing as income generating members of the family and might have a feeling of worthlessness leading to depression. Thus poor access to monetary resources and feeling of uncertainty due to poverty might be possible reasons of high rate of depression in low income population [27]. We also found obesity to be positively associated with depression. Depressed people usually adopt sedentary life style that in turn leads to weight gain and result in obesity [28].

To minimize the biases in the assessment of depression scoring and to ensure standardization, MADRS of all the subjects was done by a single health professional. Since, only subjects with high risk for diabetes as assessed by questionnaire were included in the study, our sample is not representative of the prevalence of depression in the general population.

\section{CONCLUSION}

A higher level of depression was found among subjects with newly diagnosed diabetes as opposed to subjects without diabetes but still at risk for diabetes and CVD. This is likely to be crucial for policy making. Previous studies have also largely documented higher levels of depression in those with diabetes as opposed to subjects without diabetes.
Although, our data suggests a dose-response impact of depression for diabetes, this is probably due to recruitment of subjects who already are at risk of developing diabetes as done in our diabetes prevention program. Along with diabetes, female gender and financial dependence were important factors associated with depression. Further studies are needed to determine whether psychiatric management together with lifestyle improvement may be beneficial in primary prevention of diabetes and improving glycemic control.

\section{ACKNOWLEDGEMENTS}

We acknowledge the hard work and dedicated commitment of the diabetes primary prevention team and Norwegian Research Council for financing this project. We would like to thank the Research Department of Baqai Institute of Diabetology \& Endocrinology for their valuable support.

\section{REFERENCES}

[1] International Diabetic Federation (IDF) Atlas 2006

[2] Monique MW, Ray EC, Patrick JL. Treating depression to prevent diabetes and its complications: understanding depression as a medical risk factor. Clin Diabetes 2006; 24(2): 79-6.

[3] Golden SH, Williams JE, Ford DE, et al. Depressive symptoms and the risk of type 2 diabetes: the atherosclerosis risk in communities study. Diabetes Care 2004; 27: 429 - 35.

[4] Kawakami N, Takatsuka N, Shimizu H, Ishibashi H. Depressive symptoms and occurrence of type 2 diabetes among Japanese men. Diabetes Care 1999; 22: 1071-6.

[5] Brown LC, Majumdar SR, Newman SC, Johnson JA. History of depression increases risk of type 2 diabetes in younger adults. Diabetes Care 2005; 28:1063-7.

[6] Van der AM, Schuurman A, Metsemakers J, Buntinx F. Is depression related to subsequent diabetes mellitus? Acta Psychiatr Scand 2004; 110: 178-83.

[7] Carnethon MR, Kinder LS, Fair JM, Stafford RS, Fortmann SP Symptoms of depression as a risk factor for incident diabetes: findings from the National Health and Nutrition Examination Epidemiologic Follow-Up Study, 1971-1992. Am J Epidemiol 2003; 158: 416-23.

[8] Lustman PJ, Anderson RJ, Freedland KE, de Groot M, Carney RM, Clouse RE. Depression and poor glycemic control: a meta-analytic review of the literature. Diabetes Care 2000; 23: 934-42.

[9] Anderson RJ, Freedland KE, Clouse RE, Lustman PJ. The prevalence of comorbid depression in adults with diabetes: a metaanalysis. Diabetes Care 2001; 24(6): 1069-78.

[10] de Groot M, Anderson RJ, Freedland KE, Clouse RE, Lustman PJ. Association of depression and diabetes complications: a metaanalysis. Psychosom Med 2001; 63(4): 619-30.

[11] Robert D, Pat JP, Laura JF. Diabetes, depression and quality of life. Diabetes Care 2004; 27: 1066-70.

[12] Lustman PJ, Griffith LS, Freedland KE, Kissel SS, Clouse RE. Cognitive behavior therapy for depression in type 2 diabetes: a randomized controlled trial. Ann Intern Med 1998; 129: 613-21.

[13] Mazze RS, Lucido D, Shamoon H. Psychological and social correlates of glycemic control. Diabetes Care 1984; 7: 360-6.

[14] Testa MA, Simonson DC. Health economic benefits and quality of life during improved glycemic control in patients with type 2 diabetes mellitus. JAMA 1998; 280: 1490-6.

[15] Eaton WE, Armenian H, Gallo J, Pratt L, Ford DE. Depression and risk of onset of onset of type 2 diabetes: a prospective population based study. Diabetes Care 1996; 27: 1071-6.

[16] Sandra AB, Kyriakos SM, Laura AR. Depression predicts increased incidence of adverse health outcomes in oldermexican Americans with type 2 diabetes. Diabetes Care 2003; 26: 2822-8.

[17] Jacobson AM, de Groot M, Samson JA. The effects of psychiatric disorders and symptoms on quality of life in patients with type I and type II diabetes mellitus. Qual Life Res 1997; 6: 11-20.

[18] Lloyd CE, Dyer PH, Barnett AH. Prevalence of symptoms of depression and anxiety in a diabetes clinic population. Diabet Med 2000; 17: 198-202. 
[19] Barham D, Trinder P. An improved colour reagent for the determination of blood glucose by the oxidase system. Analyst 1972; 97(151): 142-5.

[20] World Health Organization. Definition, diagnosis and classification of diabetes mellitus and its complications: report of a WHO consultation. Part 1: diagnosis and classification of diabetes mellitus. Geneva, World Health Org 1999.

[21] Montgomery SA, Asberg M. A new Depression Scale designed to be sensitive to change. Br J Psychiatry 1979; 134: 382-9.

[22] Naeem Z, Shaheen A, Bjorgulf C, Akhtar H. Depression and diabetes in a rural community in Pakistan. Diabetes Res Clin Pract 2008; 79: 124-7.

[23] Misra A. Insulin resistance syndrome (metabolic syndrome) and obesity in Asian Indians: evidence and implications. Nutrition 2004; 20: 482-91
[24] Shaheen A, Hussain A, ALI SM, Khan AK, Magnusson A. Prevalence of depression and diabetes: a population based study from rural Bangladesh. Diabet Med 2007; 24(8): 872-7.

[25] Ilyas M, Rachel J. Risk factors prevalence and treatment of anxiety of depressive disorders in Pakistan: systemic review. BMJ 2004; 328: 794

[26] Tareen E. The perception of social support and the experience of depression in Pakistani women [PhD thesis]. Colchester: University of Essex 2000.

[27] Rabbani F. Views about women's mental health: study in a squatter settlement of Karachi. J Pak Med Assoc 1999; 49(6): 139-42.

[28] Sherita HG, Janice E, Daniel EF, et al. Depressive symptoms and the risk of type 2 diabetes, the atherosclerosis risk in communities study. Diabetes Care 2004; 27(2): 429-35.

(C) Faisal et al.; Licensee Bentham Open.

This is an open access article licensed under the terms of the Creative Commons Attribution Non-Commercial License (http://creativecommons.org/licenses/by-nc/3.0/) which permits unrestricted, non-commercial use, distribution and reproduction in any medium, provided the work is properly cited. 